\title{
Journal self-citation rates in ecological sciences
}

\author{
JOCHEN KRAUSS ${ }^{\mathrm{a}, \mathrm{b}}$ \\ a Institute of Environmental Sciences, University of Zürich, Zürich (Switzerland) \\ ${ }^{\mathrm{b}}$ Department of Animal Ecology I, Population Ecology, Bayreuth (Germany)
}

\begin{abstract}
Impact factors are a widely accepted means for the assessment of journal quality. However, journal editors have possibilities to influence the impact factor of their journals, for example, by requesting authors to cite additional papers published recently in that journal thus increasing the self-citation rate. I calculated self-citation rates of journals ranked in the Journal Citation Reports of ISI in the subject category "Ecology" $(n=107)$. On average, self citation was responsible for $16.2 \pm 1.3 \%$ (mean $\pm \mathrm{SE}$ ) of the impact factor in 2004. The self-citation rates decrease with increasing journal impact, but even high impact journals show large variation. Six journals suspected to request for additional citations showed high self-citation rates, which increased over the last seven years. To avoid further deliberate increases in self-citation rates, I suggest to take journal-specific self-citation rates into account for journal rankings.
\end{abstract}

\section{Introduction}

Impact factors and citation rates are nowadays a frequently used measure for ranking the scientific quality of journals, researchers, institutes, universities and countries, even though limitations of impacts and citation rates are obvious (OPTHOF, 1997; KoKKo \& Sutherland, 1999; Kurmis, 2003; LAWrenCE, 2003; KING 2004).

Received January 30, 2007

\author{
Address for correspondence: \\ JOCHEN KRAUSS \\ Department of Animal Ecology I, Population Ecology \\ Universitätsstrasse 30, 95447 Bayreuth, Germany \\ E-mail: Jochen.Krauss@uni-bayreuth.de \\ 0138-9130/US \$20.00 \\ Copyright (C) 2007 Akadémiai Kiadó, Budapest \\ All rights reserved
}


Additionally, an increasing misuse of journal impact factors by editors, requesting authors to cite additional papers published recently in the editor's journal, has been highly criticised (HEMMINGSSON et al., 2002a; AGRAWAL, 2005). The scientific quality of a journal is generally measured in impact factors provided by ISI Web of Knowledge Journal Citation Reports and the journals are ranked separately for different subject categories. Most journal editors try to accept the best articles which fit within the scope of the journal, and these articles are often those that are most cited. However, this might not always be enough to maintain or increase the journal's impact. Apart from the ambition to lead a highly ranked journal, editors might be under pressure from publishers, because of financial constraints (LAWRENCE, 2003). This competition for money and honour has led, over the past years, to a rise in the number of editors who try to increase the impact of their journal with methods beyond simple selection of scientific quality. Four well known methods, even though many more exist, are: (1) An increasing proportion of review or mini-review articles compared to original research articles increases the impact, because reviews are on average more often cited (BAYLIS et al., 1999; KURMIS, 2003). (2) A higher number of letters, news stories, editorials etc. increases the number of citable articles, even though they are not counted in the denominator of impact factors as citable articles (GARFIELD, 1999; KURMIS, 2003). Inclusion of such material might increase the impact factor of a journal by up to $40 \%$ (ADAM, 2002). (3) There are numerous correlations between citation rates, number of authors, their country and university (LEIMU \& KORICHEVA, 2005; WONG \& KOKKO, 2005). This might lead to preference of articles by journal editors from authors, where high citation rates are expected (MONASTERSKY, 2005). (4) An increasing number of self-citations in a journal might also increase its impact (HEMMINGSSON et al., 2002a; KURMIS, 2003; CAMPANARIO \& GONZALEZ, 2006). Editorials have been used to cite numerous articles from the editors own journal, which increased the impact of a high ranked ecological journal by $20 \%$ (MONASTERSKY, 2005). In discussions with colleagues and journal editors, six journals were suggested, which participate in the practice of requesting authors to include additional citations from papers published recently in the editor's journal without any scientific justification. For the sake of argument, I used here these six journals to test, if it is possible to find evidence for enforced self-citation rates within the accessible ISI data.

Only few journal editors have openly asserted not to follow this practice, such as the editors of the Trends journals (Editor's Note, 2005) and several medicine journals e.g. the American Journal of Roentgenology (ROGERS, 2002), Acta Radiologica (PARTAIN \& FULLERTON, 2002) and the Journal of Magnetic Resonance Imaging (HEMMINGSSON et al., 2002b). There is currently no possibility to stop ambitious editors from requesting authors to cite additional articles. However, there are ways to detect irregularities by using further calculations provided by the Journal Citation Reports of ISI. Therefore I 
focus here on the following four questions, based on data of the Journal Citation Reports of ISI in the subject category "Ecology":

(1) How high are self-citation rates in general for ecological journals?

(2) Are self-citation rates correlated with journal impact factors and immediacy indices?

(3) Did self-citation rates change within the last seven years?

(4) Do self-citation rates of journals whose editors request self-citations differ from self-citation rates of other journals?

\section{Material and methods}

The data set used to calculate correlations for 2004 is based on the Journal Citation Reports of ISI Web of Knowledge in the subject category "Ecology" for the JCR Science Edition 2004 (http://portal.isiknowledge.com/). This data set contains calculations of journal impacts and immediacy indices but also data tables and figures, based on citations, for the 107 ISI ranked ecological and evolutionary journals. The cited journal data table provides detailed data on the number of cites of each journal within each year (2004-1995 plus Rest).

All equations for calculations of impact factors, immediacy indices and self-citation rates are shown in Table 1. Taking into account the number of total cites in 2004 of articles published within the last two years $(2003+2002)$ divided by the number of articles published during this time-span is called the journal's impact factor for 2004 (KURMIS, 2003). Subtracting the number of self-cites in the numerator decreases the impact and results in a self-citation adjusted impact factor (see Table 1). I call the ratio between this adjusted impact factor and the impact factor the impact relevant selfcitation rate and the ratio of all self-cites to all cites within the period the journal is ranked in ISI the total self-citation rate. A further calculation sometimes provided to rank journals is the immediacy index, which can be used to show how quickly new articles are cited. It is calculated as number of cites in the current year divided by the number of articles published in this year. As for journal impacts, I calculated an adjusted immediacy index by subtracting self-citation of each journal in the numerator. The ratio between this adjusted immediacy index and the immediacy index is called here the immediacy index relevant self-citation rate (Table 1). Correlations between these self-citation measures of the journals were calculated with Statgraphics Plus for Windows 5.1 (ANON., 2001). 
Table 1. Terms used in the text and the equations to calculate them. The equations of the impact factor and immediacy index are based on the Journal Citation Reports of ISI Web of Knowledge

impact factor $(2004)=\frac{\text { number of cites }(2002+2003)}{\text { number of articles }(2002+2003)}$

adjusted impact factor $(2004)=\frac{\text { number of cites }(2002+2003)-\text { number of self-cites }(2002+2003)}{\text { number of articles }(2002+2003)}$

impact relevant self - citation rate $(2004)$ in $\%=100-\frac{\text { adjusted impact factor }(2004)}{\text { impact factor }(2004)} * 100$

total self - citation rate $(2004)$ in $\%=\frac{\text { number of self }- \text { cites }(\text { all years })}{\text { number of cites (all years) }} * 100$

immediacy index (2004) $=\frac{\text { number of cites (2004) }}{\text { number of articles (2004) }}$

adjusted immediacy index $(2004)=\frac{\text { number of cites }(2004)-\text { number of self-cites }(2004)}{\text { number of articles }(2004)}$

immediacy index relevant self-citation rate (2004) in \% $=100-\frac{\text { adjusted immediacy index (2004) }}{\text { immediacy index }(2004)} 100$

The data set used to calculate temporal changes is based on the Journal Citation Reports of ISI Web of Knowledge in the subject category "Ecology" for the JCR Science Edition 1998-2004. Again the cited journal data table was used, but now impact relevant self-citation rates of each journal were calculated for each of the seven years. These calculations were only done for high impact journals, which were defined as an impact factor $>1$ in the year 2004 (68 journals). At least six of these journals are suggested to be encouraging journal self-citations for authors. However this selection might be incomplete and the journal names cannot be presented here as they are based on confidential discussions with authors and editors. The style and frequency of requests to cite further articles differ between the six journals and does also depend on the editor in charge (AGRAWAL, 2005; MONASTERSKY, 2005). However for the sake of argument I chose to use these six journals for comparison with other journals. To compare the self-citation rates of these six journals (all with impact factor $>1$ ) with all other high impact journals (impact factor $>1$ ) I calculated a t-test (one-sided), assuming that journals requesting further self-cites have higher self-citation rates.

Mixed effect models were calculated to identify if impact-relevant self-citation rates increase or decrease from 1998 to 2004 . I fitted a linear mixed model with impact 
relevant self-citation rate as the dependent variable and year as an explanatory fixed effect. Journal and the year x journal interaction (slope of each individual journal) were fitted as random effects. This model explained significantly more variance than a model with only journal as a random factor (Likelihood-ratio $=19.95, \mathrm{P}<0.0001$ ). The significance level of the fixed factor allowed me to infer whether impact relevant selfcitation rates increased or decreased over all journals.

To further test whether those six journals selected because they are suspected to encourage self-citations have a higher increase in self-citation rates than those that are not suspected to do so, I performed a two sample t-test (one-sided) on the best linear unbiased predictors (BLUP) of the slope for each journal, following NUSSEY et al. (2005). Mixed effect models were calculated with $R$ (version 2.1.1) (ANON., 2004). All statistics were recalculated excluding the two top ranked ecological journals Trends in Ecology and Evolution and Annual Review of Ecology Evolution and Systematics because these two journals mainly publish reviews and opinion articles. Results without the two journals are only presented in the text if the results changed substantially. Means \pm standard error, minima and maxima are presented for self-citation rates and statistical tests.

\section{Results}

The impact-relevant self-citation rate, i.e., the self-citation rate to articles published within the 2-year span preceding publication of citing articles, of the 107 ecological journals in 2004 was on average $16.2 \pm 1.3 \%$ (mean $\pm \mathrm{SE}$ ), with a minimum of $0 \%$ and maximum of $83.3 \%$. The total self-citation rate was lower with an average of $11.8 \pm 0.8 \%$, a minimum of $0 \%$ and maximum of $46.8 \%$ and the immediacy index relevant self-citation rate for 100 ranked journals in 2004 was on average $33.7 \pm 2.8 \%$, with a minimum of $0 \%$ and maximum of $100 \%$.

The impact-relevant self-citation rate was negatively correlated with the journal's impact factor of 2004 for all 107 journals (Figure 1A). This correlation however becomes insignificant for high impact journals, excluding the two top-ranked journals Trends in Ecology and Evolution and Annual Review of Ecology Evolution and Systematics $\left(\mathrm{N}=66 ; \mathrm{R}^{2}=2.30 \% ; \mathrm{p}=0.224\right)$. Similarly to the impact-relevant selfcitation rate, the total self-citation rate was negatively correlated with the journals impact factor $\left(\mathrm{N}=107 ; \mathrm{R}^{2}=8.38 \% ; \mathrm{p}=0.003\right)$, whereas the immediacy index relevant self-citation rate was positively correlated with the immediacy index (Figure 1B). This positive correlation is especially strong for high impact journals without the two topranked journals $\left(\mathrm{N}=66 ; \mathrm{R}^{2}=28.70 \% ; \mathrm{p}<0.0001\right)$. 
A)

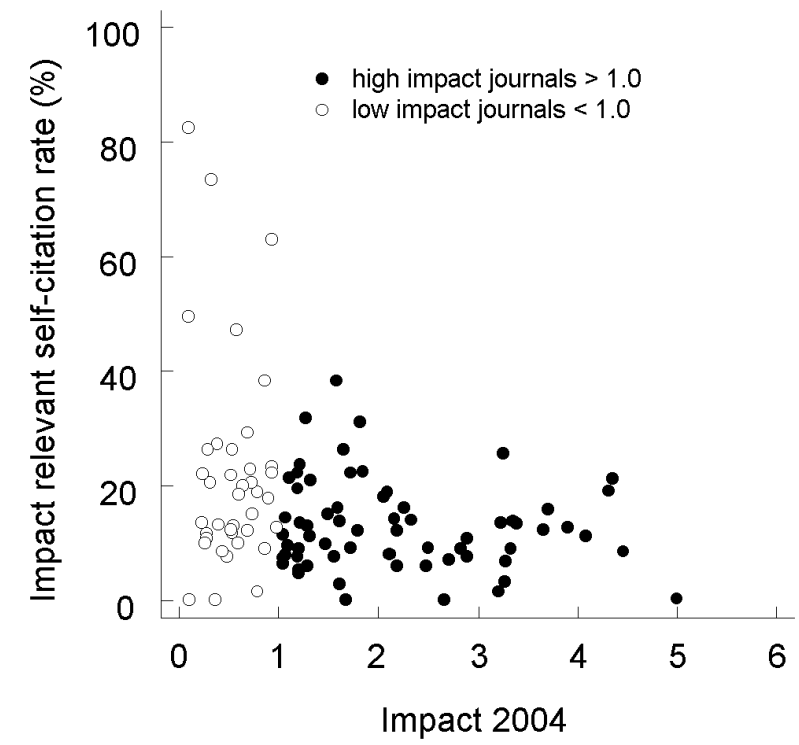

B)

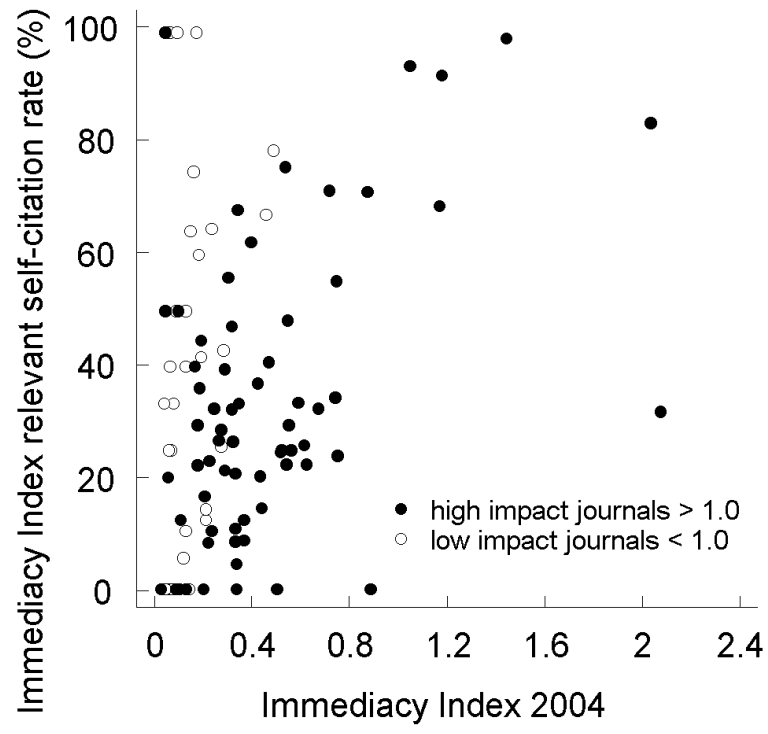

Figure 1. Correlation between impact factor or immediacy index and the self-citation rate of all 107 ISI impact ranked journals of the subject category "Ecology" in 2004.

(A) The impact relevant self-citation rate decreases with the journals impact factor $\left(\mathrm{N}=107, \mathrm{R}^{2}=8.39 \%\right.$, $\mathrm{p}=0.003$ ). Not shown are the journals Trends in Ecology and Evolution (impact factor: 12.9; self-citation rate: 4.0\%) and Annual Review of Ecology Evolution and Systematics $(9.4 ; 1.5 \%)$.

(B) The immediacy index relevant self-citation rate increases with the journals immediacy index $(\mathrm{N}=100$, $\left.\mathrm{R}^{2}=12.02 \%, \mathrm{p}=0.0004\right)$ 
In 2004, the contribution of self-citations to the journals impact of all 107 journals was on average only $0.22 \pm 0.02$, and for the 68 high impact journals (impact factor $>1$ ) it was $0.28 \pm 0.02$. The six journals encouraging self-citation enhanced their impact by self-citation on average by $0.52 \pm 0.21$, with a minimum of 0.31 and a maximum of 0.85 (Figure 2). Comparing the six ecological journals encouraging self-citation with the other 62 high impact journals, shows significant higher self-citation rates for the six journals $(20.7 \pm 3.3 \%$ compared to $11.9 \pm 1.0 \%$; one-sided $\mathrm{t}$-test; $\mathrm{t}=2.72 ; \mathrm{p}=0.004)$. The significant result is consistent also after removing the two top-ranked ecological journals $(\mathrm{p}=0.005)$ (Figure 2).

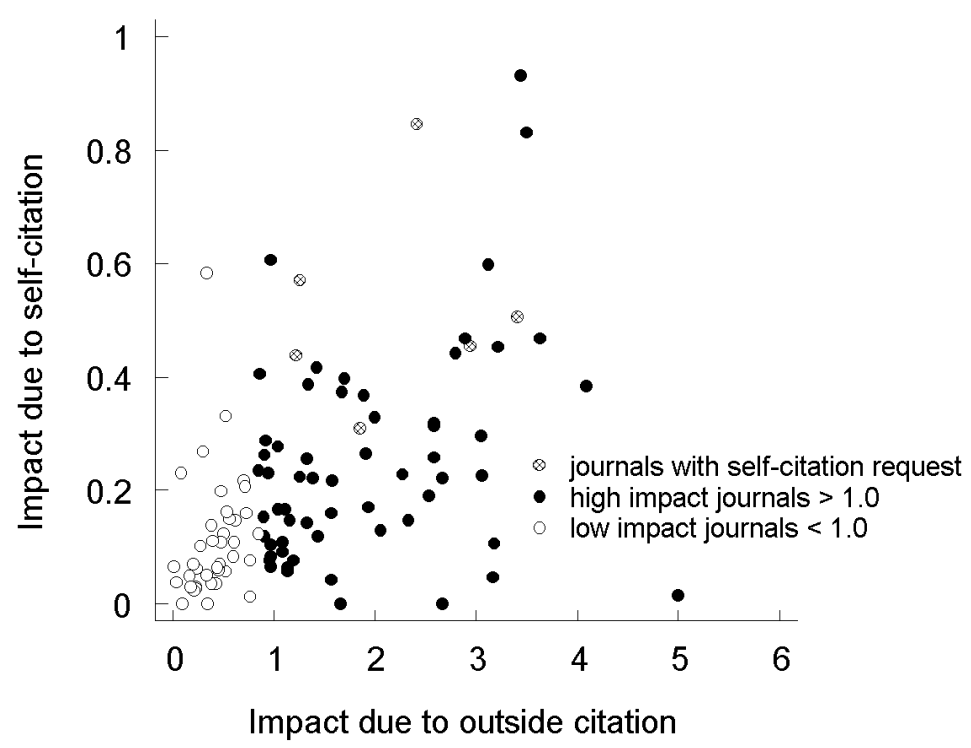

Figure 2. Impact in 2004 achieved due to self-citations (y-axis) in comparison to the impact achieved due to outside citations (x-axis). Shown are journals, where editors requested authors to include additional citations from papers published recently in the editor's journal; high impact journals (impact factor $>1$ ), where these requests are not known and journals with low impacts (impact factor $<1.0$ ). Not shown are the journals Trends in Ecology and Evolution (outside citation impact: 12.4; self-citation impact: 0.5) and Annual Review of Ecology Evolution and Systematics $(9.3 ; 0.1)$

The impact relevant self-citation rates of all journals with an impact factor $>1$ in 2004 did not significantly decrease or increase during the last seven years (1998-2004), although there is a trend towards a decrease (coefficient: $-0.348 \pm 0.183$ mean $\pm \mathrm{SE}$, 
$\mathrm{p}=0.058)$ (Figure 3 ). The average impact relevant self-citation rate changed from $12.5 \pm 1.3 \%$ (in 1998) to $14.6 \pm 1.3 \%$ (in 2000) and $12.7 \pm 1.0 \%$ (in 2004) with a peak in 2000 (significance of the quadratic term for year: Likelihood-ratio test statistic = 4.837, $\mathrm{p}<0.05)$.

Comparing the six ecological journals encouraging self-citation with other high impact journals shows an increase of impact relevant self-citation rates for the six journals compared to the other 62 journals (one-sided t-test; $\mathrm{t}=-2.02$, $\mathrm{df}=6.47$, $\mathrm{p}=0.043$; Figure 3 ). This result is consistent even after removing the two top-ranked ecological journals $(\mathrm{p}=0.041)$. One high ranked ecological journal (within the top 20 in 2004), which is accused to encourage self-citations by MONASTERSKY (2005), had a contribution of $50.4 \%$ to the journals impact in 2001 due to self-citations, only.

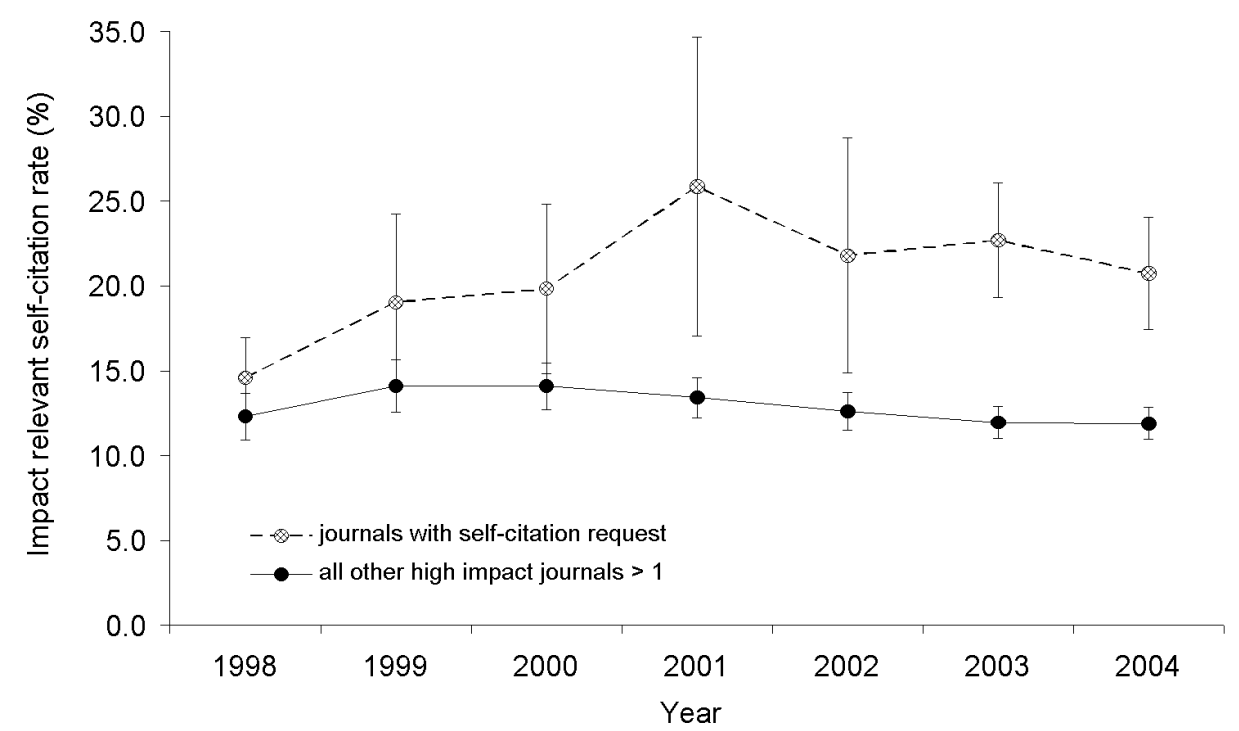

Figure 3. Mean \pm SE for impact relevant self-citation rates from $1998-2004$ of the top 68 ISI impact ranked ecological journals of the subject category "Ecology" in 2004. The journals are divided in journals, where editors requested authors to include additional citations from papers published recently in the editor's journal $(\mathrm{N}=6$ in 2004) and further high impact journals (impact factor $>1)$, where these requests are not known $(\mathrm{N}=62)$ 


\section{Discussion}

The overall journal self-citation rate of ecological journals ranked in the ISI subject category "Ecology" is on average $12 \%$. Taking into account only impact relevant selfcitation rates it is on average $16 \%$. These rates are similar to self-citation rates between 1980 - 1989 of physical sciences with $15 \%$, but higher than the rates for social sciences $6 \%$ and humanities 3\% (SNYDER \& BONZI, 1998). Multidisciplinary journals and review journals have often lower self-citation rates than isolated, new and specialised journals (ROUSSEAU, 1999). The highest ranked multidisciplinary journals in 2004 have rather low impact relevant self-citation rates (Nature: impact factor 32.18, rate 2.01; Science $31.85,1.77$; PNAS 10.45, 4.04) (ISI subject category "Multidisciplinary Sciences" for the JCR Science Edition 2004). Therefore, high quality journals can have low self-citation rates.

In this study I found that journals with higher impacts have lower self-citation rates, which supports the use of journals impact factors. However, I also showed a large amount of variation in self-citation rates, and even some of the 20 top ranked ecological journals have impact relevant self-citation rates of more than $20 \%$, with a maximum of $50 \%$ of a journal's impact caused by self-citation rates in the year 2001. These high self-citation rates are not necessarily caused only by editors encouraging authors to increase self-citations. High self-citation rates might be also caused by the high specialization of a journal (RousseaU, 1999). As shown in Figure 2 some high ranked ecological journals have high self-citation rates even though they are not suspected to encourage authors to increase journal self-citations. These journals belong often to a specific ecological subject without competition from journals with a similar scope. New journals and journals with few published articles might also have high self-citation rates as these journals are often not perceived by many scientists. These reasons for high selfcitation rates are usually not caused by the editorial board policy. However, encouraging self-citations or publishing editorials, which cite numerous articles from the editor's own journal, are obvious non scientific reasons for high self-citation rates and should be omitted (MONASTERSKY, 2005).

Another measure to rank the quality of scientific journals is the immediacy index, which positively correlates with the immediacy index relevant self-citation rate for the tested ecological journals. Furthermore the self-citation rate contributed an average of $34 \%$ to the immediacy index. Both results show the limitations of this index to rank the quality of journals without a correction for self-citation rates. I assume that the high self-citation rates within the same year in a journal are mainly caused (1) by special issues, where most articles in one issue cite each other, (2) by the article visibility for authors who want to publish in the same journal and (3) by editors requesting authors to cite recently published articles in the same journal. 
I did not detect an increase of impact relevant self-citation rates for ecological journals in general within the last 7 years. However, I found a trend towards increasing impact relevant self-citation rates of journals requesting authors to increase journal selfcitation rates. This practice causes a bias in journal ranking and is therefore highly criticized (HeMmingSSON et al., 2002a; KURMis, 2003; AGRAwal, 2005). As many editors may have just started with trying to artificially increase their journals impact with increasing self-citations, this trend might, for many journals, not be statistically detectable at the moment. Therefore it is necessary to calculate self citation rates of journals also in future years to have a control instrument and to prove whether a journal's impact is justified or mainly due to high self-citation rates.

Even though journal impacts have long been a good instrument to rank the quality of journals (GARFIELD, 1999), it is time to move on and to develop new possibilities for journal rankings which are less prone to manipulation. A first step would be the use of self-citation adjusted impact factors to increase fairness in sciences.

For helpful discussions and comments on the manuscript I thank Anurag Agrawal, Helmut Brandl, Yann Clough, Andrea Holzschuh, Christine Müller, Bernhard Schmid, Teja Tscharntke, Jason Tylianakis, Klaas Vrieling and many further colleagues. Yann Clough and Bernhard Schmid improved the quality of the statistical analyses.

\section{References}

ADAM, D. (2002), The counting house. Nature, $415: 726-729$.

Agrawal, A. A. (2005), Corruption of journal impact factors. Trends in Ecology and Evolution, 20 : 157.

ANON (2001), Statgraphics Plus for Windows, ver. 5.1. Manugistics, Rockville, MD, USA.

ANON (2004), R: a language and environment for statistical computing. R Foundation for Statistical Computing, Vienna, Austria. (URL http://www.R-project.org/)

BAYLIS, M., GRAVENOR, M., KAO, R. (1999), Sprucing up one's impact factor. Nature, 401 : 321-322.

CAmpanario, J. M., Gonzalez, L. (2006), Journal self-citations that contribute to the impact factor: documents labeled "editorial material" in journals covered by Science Citation Index. Scientometrics, $69: 365-386$.

Editor's Note (2005), Trends in Ecology and Evolution, 20 : 157.

GARFIELD, E. (1999), Journal impact factor: A brief review. Canadian Medical Association Journal, $161: 979-980$.

Hemmingsson, A., Edgren, J., Mygind, T., SkJennald, A. (2002b), Impact factors in scientific journals. Journal of Magnetic Resonance Imaging, $15: 619$.

Hemmingsson, A., Mygind, T., SkJennald, A., Edgren, J. (2002a), Manipulation of impact factors by editors of scientific journals. American Journal of Roentgenology, $178: 767$.

KING, D. A. (2004), The scientific impact of nations. Nature, $430: 311-316$.

KoKKo, H., SuTherland, W. J. (1999), What do impact factors tell us? Trends in Ecology and Evolution, $14: 382-384$.

KURMIS, A. P. (2003), Understanding the limitations of the journal impact factor. Journal of Bone and Joint Surgery - American Volume, 85 : 2449-2454.

LAWRENCE, P. A. (2003), The politics of publication. Nature, $422: 259-261$. 
J. KRAUSS: Journal self-citation rates in ecological sciences

LeIMU, R., KoricheVA, J. (2005), What determines the citation frequency of ecological papers? Trends in Ecology and Evolution, $20: 28-32$.

Monastersky, R. (2005), The number that's devouring science. The Chronicle of Higher Education, 52 : A12. (14 October 2005; http://chronicle.com/free/v52/i08/08a01201.htm)

Nussey, D. H., Clutton-Brock, T. H., Elston, D. A., Albon, S. D., Kruuk, L. E. B. (2005), Phenotypic plasticity in a maternal trait in red deer. Journal of Animal Ecology, $74: 387-396$.

OPTHOF, T. (1997), Sense and nonsense about the impact factor. Cardiovascular Research, 33 : 1-7.

PARTAin, C. L., Fullerton, G. D. (2002), Editor's Note. Journal of Magnetic Resonance Imaging, 15 : 619.

ROGERS, L. F. (2002), From the editor's notebook; impact factor: the numbers game. American Journal of Roentgenology, $178: 541-542$.

Rousseau, R. (1999), Temporal differences in self-citation rates of scientific journals. Scientometrics, $44: 521-531$.

SNYDER, H., BONZI, S. (1998), Patterns of self-citation across disciplines. Journal of Information Science, $24: 431-435$.

Wong, B. B. M., KокKо, H. (2005), Is science as global as we think? Trends in Ecology and Evolution, $20: 475-476$. 